\title{
Morphology and pore structure of zirconia particles prepared by the thermal treatment of zirconium tetra- $n$-propoxide in glycols
}

\author{
Fuya SUGIYAMA ${ }^{1}$ and Shinji IWAMOTO' ${ }^{1, \dagger}$ \\ ${ }^{1}$ Division of Molecular Science, Graduate School of Science and Technology, Gunma University, Kiryu, Gunma 376-8515, Japan
}

Zirconia particles were prepared by thermal treatment of zirconium(IV) tetra-n-propoxide (ZNP) in $\mathrm{C}_{2}-\mathrm{C}_{6}$ glycols (Glycothermal method) at $300{ }^{\circ} \mathrm{C}$ and morphology and pore structures of the products were examined. $\mathrm{X}$ ray diffraction results revealed that nanocrystals of tetragonal zirconia phase were mainly obtained in all cases. However, the morphology and pore structures of the products were quite different depending on the glycols used. The products prepared in 1,4-butanediol (1,4-BG) were spherical particles with ca. $5 \mu \mathrm{m}$ size while aggregations of fine particles were observed for other glycols. The samples obtained in 1,4-BG had large surface areas and showed narrow pore-size distributions in the mesopore region. To investigate the formation process of the products having such a unique morphology and pore system, the mixtures of ZNP and glycols were heated at lower temperatures. It was found that the thermal reaction of $\mathrm{ZNP}$ in 1,4-BG at $20{ }^{\circ} \mathrm{C}$ afforded intermediates with layered structures, which subsequently changed into nanocrystalline $\mathrm{ZrO}_{2}$ at elevated temperatures. These stepwise crystallization processes attribute to the unique morphology and pore system of the products obtained by the thermal treatment of ZNP in 1,4-BG.

(O2020 The Ceramic Society of Japan. All rights reserved.

Key-words : $\mathrm{ZrO}_{2}$, Glycothermal method, Spherical particles, Pore structure

\section{Introduction}

Zirconia and zirconia-based oxides have been used as catalysts and catalysts supports for various reactions, ${ }^{1)-5}$ ) and to improve their performance, control of the pore structure of these materials is greatly important. Besides catalytic applications, zirconia have been also collecting much attention as stationary phase supports for liquid chromatography, ${ }^{6)-8)}$ and synthesis of spherical zirconia particles with homogeneous size and shapes were investigated. ${ }^{9), 10)}$ A sol-gel method is one of the preferable methods for this purpose; however, the obtained products are amorphous or oxides with low crystallinity, and therefore, heat treatments are necessary to obtain wellcrystallized products. ${ }^{11), 12)}$ On the contrary, Inoue et al. previously reported that microcrystalline zirconias with high surface areas were directly obtained by the thermal reaction of zirconium(IV) tetra- $n$-propoxide (ZNP) in various organic solvents. ${ }^{13)}$ Furthermore, thermal reactions of ZNP in 1,4-butanediol (1,4-BG) and 1,5-pentanediol $(1,5-\mathrm{PeG})$ were examined, and it was found that spherical zirconia particles composed of nanocrystalline zirconias were directly obtained by using 1,4-BG. ${ }^{14)}$ Influence of synthesis conditions on the physical property of the zirconia powders were examined; however, the effect of

\footnotetext{
Corresponding author: S. Iwamoto; E-mail: siwamoto@ gunma-u.ac.jp
}

the solvents and the pore structure of the calcined products was not evaluated sufficiently. In this study, zirconia samples were prepared by heating ZNP in various glycols, ethylene glycol (EG), 1,3-propanediol (1,3-PrG), 1,4-BG, 1,5-PeG, and 1,6-hexanediol (1,6-HG) at $300^{\circ} \mathrm{C}$ and the morphology and pore structures of the products and those after calcination at higher temperatures were investigated. Furthermore, to elucidate the reasons for the difference of the morphology and pore structures of the products, thermal treatments at low temperature were conducted.

\section{Experimental}

Zirconium tetra- $n$-propoxide (ZNP, $19.7 \mathrm{~g}$, Mitsuwa's Pure Chemicals) was added in the solvent, EG, 1,3-PrG, 1,4-BG, 1,5-PeG, or 1,6-HG $(100 \mathrm{~mL})$ and the mixture in a test tube was then set in a $300-\mathrm{mL}$ autoclave. An additional $30 \mathrm{~mL}$ of the solvent was added in the gap between the test tube and the autoclave wall. After the atmosphere inside the autoclave was replaced with nitrogen, the mixture was heated to $300^{\circ} \mathrm{C}$ at a rate of $2.5^{\circ} \mathrm{C} / \mathrm{min}$, and kept at that temperature for $2 \mathrm{~h}$ under the autogenous pressure of the solvent. After the thermal reaction for $2 \mathrm{~h}$, the valve of the autoclave was slightly opened to remove organic vapor from the autoclave by flashing evaporation while keeping the temperature at $300{ }^{\circ} \mathrm{C} .{ }^{15)}$ After cooling, dry powders were obtained directly. The obtained products were calcined at prescribed temperatures $(300,400,500$, and $600{ }^{\circ} \mathrm{C}$ ) for $1 \mathrm{~h}$ in a box furnace. To examine the 
formation process of the pore system, the thermal treatments of ZNP in various glycols were also conducted at lower temperatures.

Powder X-ray diffraction (XRD) patterns were collected on a Rigaku RINT $2200 \mathrm{VF}$ using $\mathrm{Cu} \mathrm{K} \alpha$ radiation and the crystallite sizes of the samples were calculated from the half-width of the diffraction peaks by Scherrer's method. Scanning electron microscopy (SEM) observation was performed on a JEOL JSM-6510AS. Specific surface areas were calculated using the BET multipoint method with a Quantachrome Instruments NOVA 2200e. Pore size distributions were calculated on the basis of $\mathrm{N}_{2}$ adsorption isotherms using the BJH method. Simultaneous thermogravimetric and differential thermal analyses (TG-DTA) were performed on a thermal analyzer, Seiko Instruments Inc. TG/DTA6200, at a rate of $10^{\circ} \mathrm{C} / \mathrm{min}$ in a $\mathrm{N}_{2}$ flow. Analysis of $\mathrm{C}$ and $\mathrm{H}$ contents were conducted using a CHN element analyzer J-Science Lab Micro Corder JM10.

\section{Results and discussion}

In Fig. 1, XRD patterns of as-synthesized products obtained by the glycothermal method using various glycols and the samples after the calcination at $500^{\circ} \mathrm{C}$ are shown.
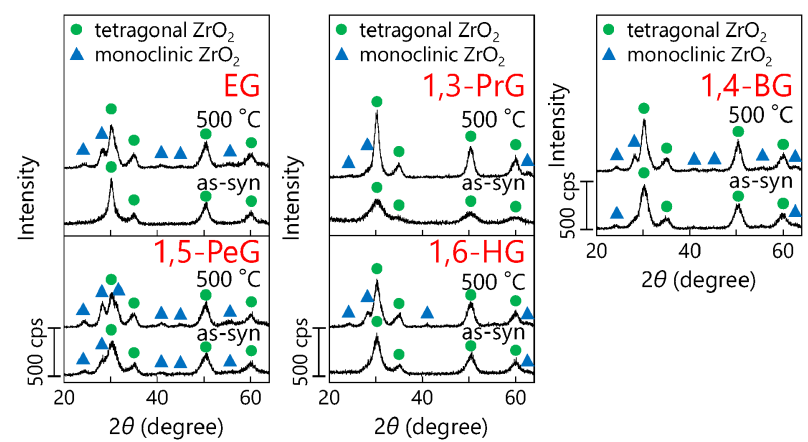

Fig. 1. XRD patterns of the products obtained by the thermal treatment of ZNP in various glycols, and the samples after calcination in air at $500{ }^{\circ} \mathrm{C}$.
For the as-synthesized products, broad diffraction peaks assigned to the tetragonal $\mathrm{ZrO}_{2}$ phase were mainly observed. The crystallite size of the product obtained in 1,4BG was ca. $5 \mathrm{~nm}$ which is good agreement with the crystallite sizes reported in the previous study. ${ }^{13)}$ After the calcination at $500^{\circ} \mathrm{C}$, sharpening of the peaks and transformation from the tetragonal $\mathrm{ZrO}_{2}$ phase to the monoclinic $\mathrm{ZrO}_{2}$ phase were observed.

In Fig. 2, SEM images of the products are depicted. For the product prepared in EG, 1,3-PrG, 1,5-PeG, and 1,6$\mathrm{HG}$, aggregation of fine particles and no spherical secondary particles were observed. On the contrary, for the products synthesized in 1,4-BG, spherical particles with particle size of $\sim 5 \mu \mathrm{m}$ were observed. After the calcination at high temperatures, the spherical shapes were preserved though particle sizes became slightly small (Fig. S1).

Figure 3 shows the $\mathrm{N}_{2}$ adsorption isotherms and pore size distributions of the calcined samples obtained by the glycothermal method. For the samples synthesized in EG, large pore volumes were attained. The pore size distribution was observed in a wide range for these samples. For the products prepared in 1,3-PrG or 1,6-HG, pore volumes were small and pore size distribution peaks were observed in a relatively small region. For the samples obtained in 1,5-PeG, macropores were observed in addition to small pores in the range of $1-5 \mathrm{~nm}$. On the contrary, for samples obtained in 1,4-BG, apparent hysteresis loops were observed in the isotherm. The shapes of the isotherms are classified as type IV, and pore size distribution peaks are obtained in the mesopore region. As the crystallite sizes of the obtained zirconias are ca. $5 \mathrm{~nm}$, it is considered that the formation of these mesopores are attributed to the space between coagulated particles.

In Fig. 4, $V$ - $t$ plots derived from the isotherms for the zirconia samples after calcination at $500^{\circ} \mathrm{C}$ are depicted, and physical properties of them are summarized in Table 1. The sample synthesized in 1,4-BG possesses a larger surface area compared with those prepared in other
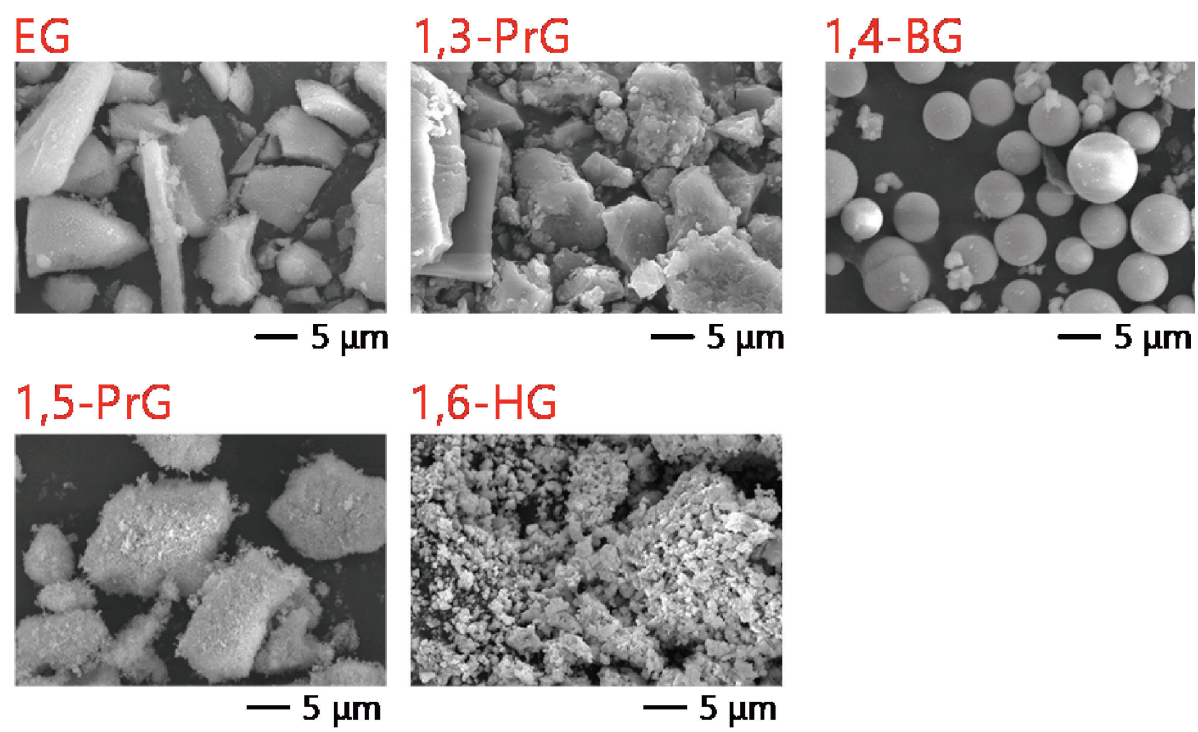

Fig. 2. SEM images of the products prepared by the thermal treatment of ZNP in various glycols. 

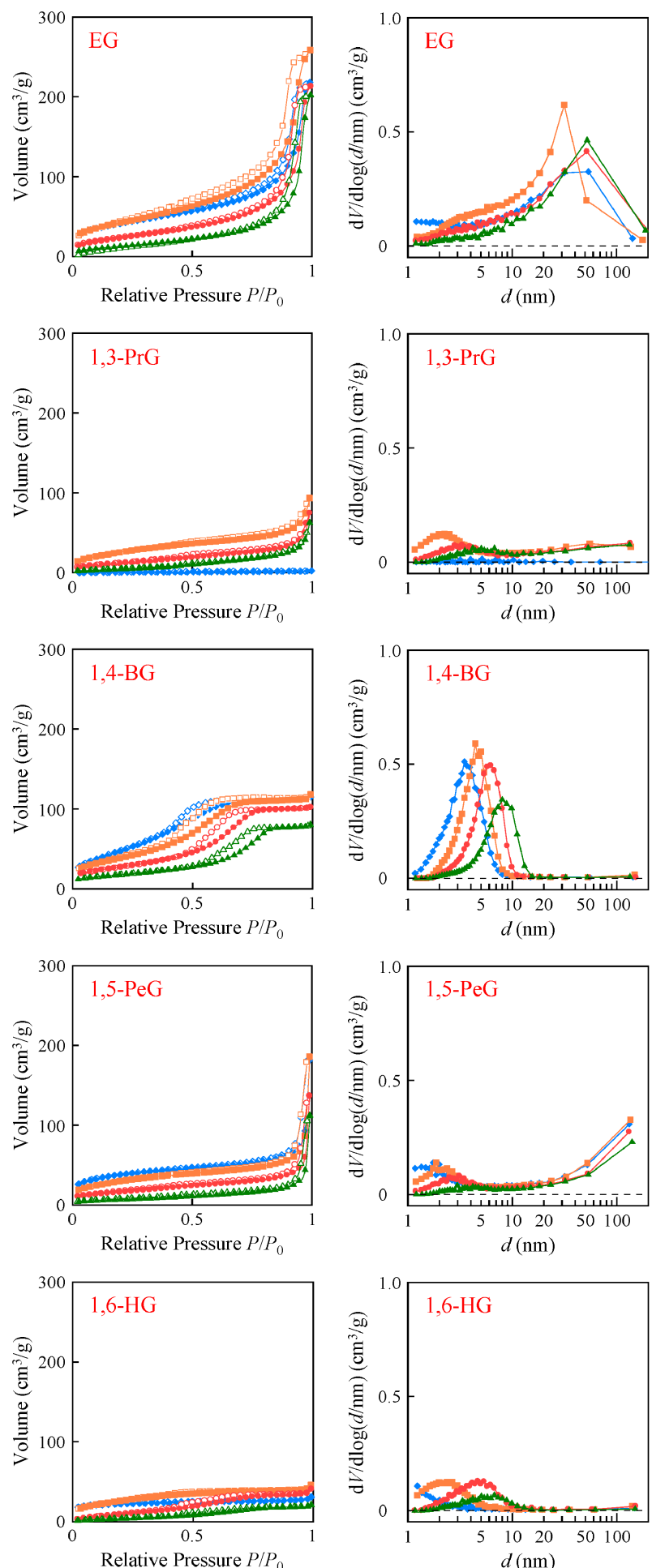

Fig. 3. $\mathrm{N}_{2}$ adsorption isotherm and pore size distribution of the zirconia samples prepared in various glycols, followed by calcination in air at: $\diamond, \diamond: 300^{\circ} \mathrm{C}, \square, \sqcap: 400^{\circ} \mathrm{C}, \diamond, \bigcirc: 500^{\circ} \mathrm{C}$, and $\Delta, \triangle: 600^{\circ} \mathrm{C}$; closed symbols: adsorption, open symbols: desorption.

glycols. Pore volumes for the zirconias obtained in EG, 1,3-PrG, and 1,5-PeG were relatively large; however, they were mostly in the macropore region. On the contrary, the zirconia samples obtained in 1,4-BG showed a large pore volume in the mesopore region. It should be also noted

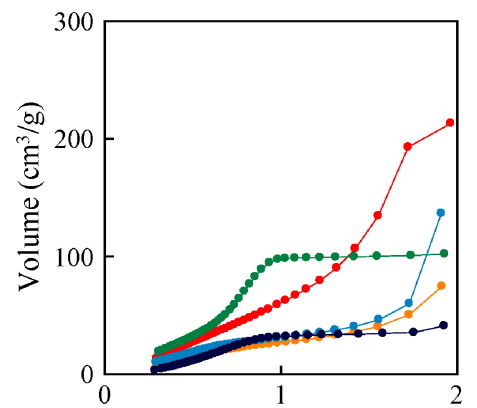

de Boer Statistical Thickness (nm)

Fig. 4. $V-t$ plots derived from the adsorption branch of the isotherm of the zirconias after calcination at $500^{\circ} \mathrm{C}$ in air. $\mathrm{EG}$,

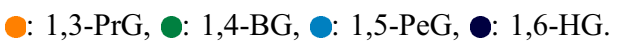

Table 1. Physical properties of the zirconias after calcination at $500{ }^{\circ} \mathrm{C}$ in air

\begin{tabular}{ccccccc}
\hline \multirow{2}{*}{ Solvent } & \multicolumn{3}{c}{ Specific surface area $\left(\mathrm{m}^{2} / \mathrm{g}\right)$} & & \multicolumn{2}{c}{ Pore volume $\left(\mathrm{cm}^{3} / \mathrm{g}\right)$} \\
\cline { 2 - 4 } \cline { 6 - 7 } & BET & Mesopore* & External* & & Total & Mesopore* \\
\hline EG & 56.6 & n. d. & n. d. & & 0.33 & n. d. \\
1,3-PrG & 45.1 & 18.6 & 26.5 & & 0.12 & 0.02 \\
$1,4-\mathrm{BG}$ & 111 & 106 & 4.9 & & 0.16 & 0.15 \\
$1,5-\mathrm{PeG}$ & 58.9 & 28.6 & 30.3 & & 0.21 & 0.02 \\
$1,6-\mathrm{HG}$ & 41.3 & 36.2 & 5.1 & & 0.06 & 0.05 \\
\hline
\end{tabular}

${ }^{*}$ Calculated from the $V-t$ plots.
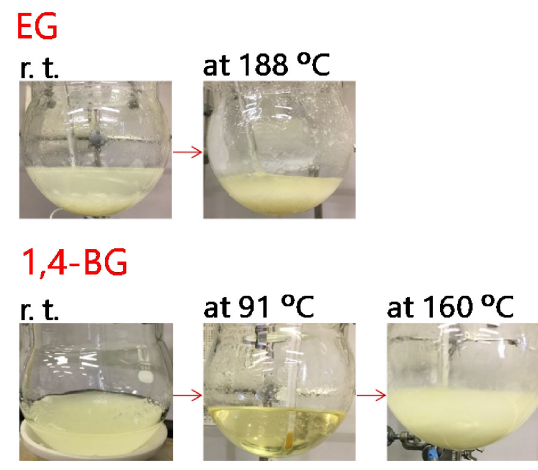

$1,5-\mathrm{PeG}$

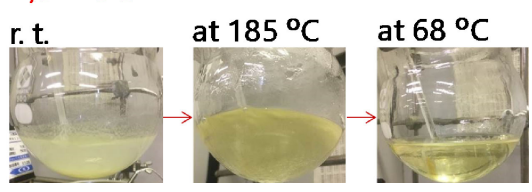

Fig. 5. Changes of the ZNP in various glycols by heating at lower temperatures.

that these samples have quite a small pore volume in the size larger than $20 \mathrm{~nm}$. This feature is also seen in the $V-t$ plot as shown in Fig. 4. These results suggest that the pore texture of the product obtained in 1,4-BG is formed via different processes from those obtained in other glycols.

To investigate the formation mechanism of the pore system, the thermal treatments of ZNP in various glycols were carried out at lower temperatures in glass vessels, and the changes observed are shown in Fig. 5 and Fig. S2. When ZNP was added to EG, precipitates were formed, and the precipitates remained up to ca. $190^{\circ} \mathrm{C}$. In Fig. S3, 
XRD patterns of the products by the thermal treatment of ZNP at $200^{\circ} \mathrm{C}$ are shown. The precipitates obtained in EG showed only broad peaks, suggesting they have low crystallinity. When the mixture of ZNP and 1,5-PeG were heated, a yellow transparent solution was obtained at ca. $185^{\circ} \mathrm{C}$. A clear solution was obtained even after the mixture was cooled down to room temperature. Even after heating up to $200^{\circ} \mathrm{C}$, only a small amount of precipitates was observed. For ZNP, formation of tetrametric $\mathrm{Zr}_{4}(\mathrm{OPr})_{16}$ was reported $^{16)}$ in organic solvents. Therefore, it was presumed that zirconia nanocrystals are formed from such soluble species in the case of $1,5-\mathrm{PeG}$. On the contrary, when the mixture of ZNP and 1,4-BG was heated, a transparent solution was obtained at ca. $90^{\circ} \mathrm{C}$, and then white precipitates were formed at ca. $150^{\circ} \mathrm{C}$ (Fig. 5).

In Fig. 6(a), the XRD patterns of the white precipitates obtained by the thermal treatment of ZNP in 1,4-BG at 200 and $250^{\circ} \mathrm{C}$ are shown. Two sharp diffraction peaks are observed for both samples. Especially, for the product obtained by heating at $250^{\circ} \mathrm{C}$, strong and sharp peaks were observed at 7.22 and $8.32^{\circ}$, which correspond to lattice spacings of 12.2 and $10.6 \AA$, respectively. Such large lattice spacings indicate the formation of substances with a layered structure. The TG profiles for these products are shown in Fig. 6(b). For the product obtained at $200^{\circ} \mathrm{C}$, two large weight losses were observed at round 150 and $400{ }^{\circ} \mathrm{C}$; the former would be due to the desorption of water and the latter to decomposition of organic moieties included in the sample. For the product obtained after heating at $250{ }^{\circ} \mathrm{C}$, ca. $33 \%$ weight loss was observed up to $600{ }^{\circ} \mathrm{C}$, which indicates the $\mathrm{ZrO}_{2}$ content is ca. $67 \%$. The
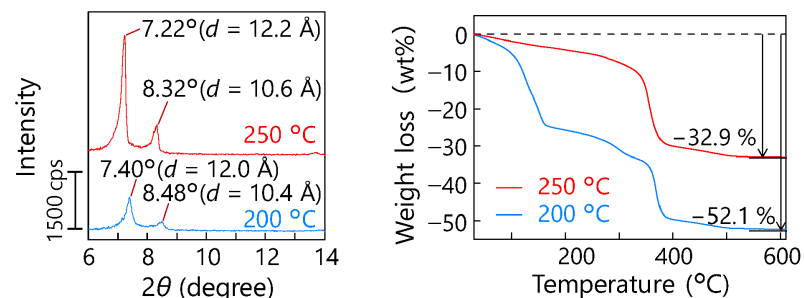

Fig. 6. XRD patterns (a) and TG profiles (b) of the products by the thermal treatment of ZNP in $1,4-B G$ at 200 and $250^{\circ} \mathrm{C}$. chemical analysis shows this product contains $4.1 \%$ of $\mathrm{H}$ and $21.1 \%$ of $\mathrm{C}$. From these results, we presume the products has a layered structure as shown in Fig. 7. For the thermal reactions of metal alkoxides in 1,4-BG, for example aluminum isopropoxide, substitution of alkoxides with glycoxides and subsequent heterolytic cleavage of the $\mathrm{O}-\mathrm{C}$ bonds of the glycoxides to form $\mathrm{M}-\mathrm{O}-\mathrm{M}$ bonds with releasing tetrahydrofuran (THF) was suggested. ${ }^{17), 18)}$ Similar reactions are also expected to take place in the present case of ZNP and 1,4-BG. However, as mentioned above, thermal reaction of ZNP in 1,4-BG afforded a clear solution and then intermediates with a layer structure. Therefore, the first step at the early stage of the reactions is supposed to be the substitution of propoxides with 1,4$\mathrm{BG}$ to form tetrametric Zr-glycoxide species, which would be soluble in the organic media in the present system. Secondly, by connecting these species with releasing THF molecules, $\mathrm{Zr}-\mathrm{O}-\mathrm{Zr}$ bonds are newly formed, which affords the formation of layered structures. For glycols lower than $\mathrm{C} 4$, similar reactions are unlikely to occur since cyclic ethers of $\mathrm{C} 2$ or $\mathrm{C} 3$ are not stable. On the other hand, for the 1,6-HG, formation of a seven-membered ring is difficult because of the proximity effect of transannular hydrogen atoms. ${ }^{19)}$ In the case of $1,5-\mathrm{PeG}$, formation of six-membered cyclic ether is likely to occur; however, only a small amount of precipitate was observed up to $200^{\circ} \mathrm{C}$, which suggest soluble glycoxide intermediates are stable at this temperature.

For formation of particles with a spherical morphology, a droplet formation process would be indispensable. As the intermediates include considerably large amounts of organic moieties, they may melt to form droplets at elevated temperatures, and the crystallization to $\mathrm{ZrO}_{2}$ nanocrystals proceeds via the decomposition of glycoxides in the droplets of the intermediates with releasing THF molecules. Due to such stepwise reactions, nanocrystalline $\mathrm{ZrO}_{2}$ particles are partly bound to each other to form voids in the mesopore region between the particles.

\section{Conclusions}

In summary, spherical $\mathrm{ZrO}_{2}$ particles with developed mesopores were directly obtained via thermal treatment of (a)

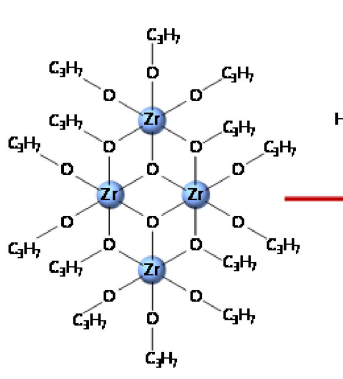

(b)

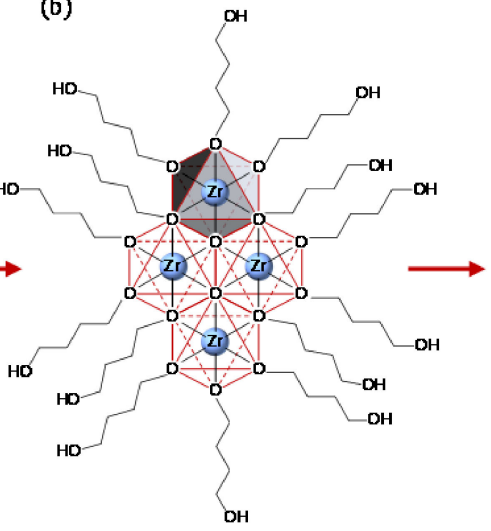

(c)

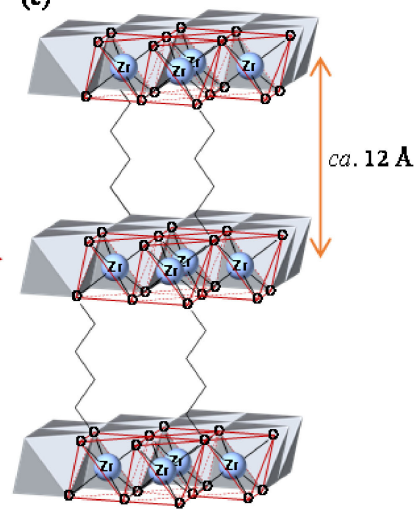

Fig. 7. A predicted structure of the product by heating of ZNP in 1,4-BG at lower temperatures. 
$\mathrm{ZNP}$ in $1,4-\mathrm{BG}$ at $300^{\circ} \mathrm{C}$ for $2 \mathrm{~h}$. At lower temperatures, $\mathrm{ZNP}$ reacts with $1,4-\mathrm{BG}$ to form glycoxide-containing intermediates with a layered structure, which then decompose to crystalline $\mathrm{ZrO}_{2}$ at higher temperatures. Such a stepwise crystallization mechanism attributed to the unique morphology and pore system of the product. Using the obtained $\mathrm{ZrO}_{2}$ particles, superior properties in various applications, especially in catalysis and chromatography, are expected.

Acknowledgement The work was partly supported by a research grant from Suzuki Foundation and the promotion of university-industry collaborative research based on regulatory sciences, Gunma university. The XRD mesurement was performed by a Rigaku RINT 2200VF at the Center for Instrumental Analysis of Gunma University. We thank Prof. S. Shiraishi (Gunma University) for use of SEM, JEOL JSM-6510AS.

\section{References}

1) H. Matsuhashi, H. Nakamura, T. Ishihara, S. Iwamoto, Y. Kamiya, J. Kobayashi, Y. Kubota, T. Yamada, T. Matsuda, K. Matsushita, K. Nakai, H. Nishiguchi, M. Ogura, N. Okazaki, S. Sato, K. Shimizu, T. Shishido, S. Yamazoe, T. Takeguchi, K. Tomishige, H. Yamashita, M. Niwa and N. Katada, Appl. Catal. A-Gen., 360, 8997 (2009).

2) J. D. A. Bellido, J. E. De Souza, J. M'Peko and E. M. Assaf, Appl. Catal. A-Gen., 358, 215-223 (2009).

3) H. Liu and E. Iglesia, J. Phys. Chem. B, 109, 21552163 (2005).

4) M. D. Rhodes and A. T. Bell, J. Catal., 233, 198-209
(2005).

5) D. E. López, J. G. Goodwin, Jr., D. A. Bruce and S. Furuta, Appl. Catal. A-Gen., 339, 76-83 (2008).

6) B. Yan, C. V. McNeff, P. W. Carr and A. V. McCormick, J. Am. Ceram. Soc., 88, 707-713 (2005).

7) A. Pattanayak and A. Subramanian, Powder Technol., 192, 359-366 (2009).

8) B. Yan, C. V. McNeff, F. Chen, P. W. Carr and A. V. McCormick, J. Am. Ceram. Soc., 84, 1721-1727 (2001).

9) C. Zhang, C. Li, J. Yang, Z. Cheng, Z. Hou, Y. Fan and J. Lin, Langmuir, 25, 7078-7083 (2009).

10) H. Uchiyama, K. Takagi and H. Kozuka, Colloid. Surface. A, 403, 121-128 (2012).

11) J. A. Wang, M. A. Valenzuela, J. Salmones, A. Vázquez, A. Garacía-Ruiz and X. Bokhimi, Catal. Today, 68, 21-30 (2001).

12) M. Shane and M. L. Mecartney, J. Mater. Sci., 25, 1537-1544 (1990).

13) M. Inoue, H. Kominami and T. Inui, Appl. Catal. AGen., 97, L25-L30 (1993).

14) S. Kongwudthiti, P. Praserthdam, P. Silveston and M. Inoue, Ceram. Int., 29, 807-814 (2003).

15) S. Iwamoto, K. Saito, M. Inoue and K. Kagawa, Nano Lett., 1, 417-421 (2001).

16) V. W. Day, W. G. Klemperer and M. M. Pafford, Inorg. Chem., 40, 5738-5746 (2001).

17) M. Inoue, H. Kominami and T. Inui, Res. Chem. Intermediat., 24, 571-579 (1998).

18) M. Inoue, H. Kominami and T. Inui, J. Chem. Soc., Dalton Trans., 3331-3336 (1991).

19) M. Inoue, J. Phys. Condens. Matter, 16, S1291-S1303 (2004). 